\title{
Dinámica de la Leucosis Bovina en el ganado criollo Hartón del Valle en infección natural
}

\author{
Hernandez, D ${ }^{1} ;$ Muñoz, J² y Álvarez, L²
}

'Departamento de Zootecnia. Facultad de Ciencias Agropecuarias. Universidad de Sucre. Sincelejo. Colombia. ${ }^{2}$ Facultad de Ciencias Agropecuarias. Universidad Nacional de Colombia. Palmira. Colombia.

PALABRAS CLAVE ADICIONALES

Carga proviral.

Ganado criollo colombiano.

Resistencia a enfermedades.

\section{ADDITIONAL KEYWORDS \\ Proviral load. \\ Colombian creole cattle. \\ Disease resistance.}

INFORMACIÓN

Cronología del artíiculo.

Recibido/Received: 06.01 .2016

Aceptado/Accepted: 16.03.2016

On-line: 15.09 .2016

Correspondencia a los autores/Contact e-mail:

darwin.hernandez@unisucre.edu.co

\begin{abstract}
RESUMEN
Los bovinos criollos presentan características adaptativas de importancia. Se ha propuesto que el desarrollo y/o progresión de la leucosis bovina tiene bases genéticas. En el presente trabajo se estudió la dinámica del virus de la leucosis bovina en el ganado criollo Hartón del Valle en condiciones de infección natural. En 93 animales Hartón del Valle (HV), 30 Lucerna (LUC) y 30 Holstein (HOL) se evaluó la presencia del VLB por PCR-anidada, el desarrollo de linfocitosis por extendido en placa, los títulos de anticuerpos usando ELISA y la carga proviral mediante PCR en tiempo real, en tres muestreos durante un año. Se estimaron los porcentajes de animales infectados y se realizaron pruebas de independencia entre las variables evaluadas. Se encontró un efecto racial significativo sobre el desarrollo de la leucosis bovina, los animales de la raza Hartón presentaron menor tasa de infección del VLB $(38,3 \%)$, desarrollaron menos linfocitosis persistente (15\%), tuvieron mayores títulos de anticuerpos contra el virus $(97,6)$ y mantuvieron la carga proviral más baja $(663828$ copias/ng de ADN) que las razas Lucerna y Holstein. Los datos aquí presentados pueden ser utilizados en programas de erradicación y control de la enfermedad. Se concluye que el ganado criollo Hartón del Valle puede ser considerado un progresor lento de la leucosis bovina.
\end{abstract}

\section{Dynamics of Bovine leukosis in creole cattle Hartón del Valle in natural infection}

\section{SUMMARY}

Creole cattle have important adaptive features. It has been proposed that the development and/or progression of bovine leukemia has a genetic basis. In this paper, the dynamics of bovine leukemia virus in Creole Hartón del Valle cattle under natural infection conditions was studied. The presence of VLB-nested PCR, lymphocytosis development by spread plate, antibody titers evaluated using ELISA and proviral load through real-time PCR, were assessed in 93 Hartón Valley (HV), 30 Lucerna (LUC) and 30 Holstein (HOL) animals, in three samples for one year. The percentage of infected animals were estimated and independence tests were performed among the evaluated variables. A breed significant effect was found on the development of bovine leukemia, the Hartón del Valle breed animals showed a lower infection rate VLB $(38.3 \%)$, developed a less persistent lymphocytosis $(15 \%)$, had higher titers of virus antibodies (97.6) and kept the lowest proviral load (663828 copies/ng of DNA) when comparing it to Lucerne and Holstein breeds. The data presented here can be used in eradication and disease control programmes. It is concluded Hartón del Valle creole cattle may be considered a slow bovine leukemia progressor.

\section{INTRODUCCIÓN}

La leucosis bovina enzoótica (LBE), es una enfermedad infecciosa producida por un retrovirus, el virus de la leucosis bovina (VLB), que afecta las células de la línea linfoide, los linfocitos "B" (Beyer et al., 2002; Baruta et al., 2011;). Es una enfermedad linfoproliferativa y se caracteriza por presentar linfocitosis persistente (LP) que se manifiesta con un incremento sostenido del número absoluto de linfocitos en la corriente sanguínea la cual aparece con una frecuencia de entre el 30 y $70 \%$ de los animales infectados; tumores (linfosarcoma o linfoma maligno) en los bovinos mayores a 3 años con una frecuencia de ocurrencia de entre 0.1 y $10 \%$ y una forma en la cual los animales tienen anticuerpos (antiVLB) sin linfocitosis persistente, ni lesiones tumorales condición conocida como fase Aleucemica (Chamizo, 2005; Cadavid 2012). Entre otros síntomas se cuentan el aumento bilateral más o menos simétrico de los ganglios linfáticos explorables (Shell y Muller, 2004), la exoftalmia por la afección del tejido retro-ocular o de las estructuras internas del ojo, pueden considerarse como una manifestación específica de la enfermedad, así como la presencia de masas linfoadenopatías sub- 
Tabla I. Número de animales por raza y rangos de edades de los individuos estudiados (Number of animals by race and age ranges of studied individuals).

\begin{tabular}{cccccccc}
\hline Raza & \multicolumn{3}{c}{ Sexo } & \multicolumn{3}{c}{ Rangos de edad } & \multirow{N}{*}{$N$} \\
\cline { 2 - 5 } & \multirow{0}{*}{} & + & $<2$ años & $2-4$ años & $>4$ años & \\
\hline HV & 7 & 86 & 28 & 31 & 34 & 93 \\
LUC & 6 & 24 & 10 & 10 & 10 & 30 \\
HOL & 5 & 25 & 16 & 6 & 8 & 30 \\
\hline
\end{tabular}

cutáneas en diferentes localizaciones (linfoadenopatías) (Malatestinic, 2003; Chamizo, 2005).

El VLB pertenece a la familia de los Retroviridae, del género Deltaretrovirus y como tal posee una transcriptasa reversa responsable de la síntesis de una copia de ADN a partir de ARN viral. El ADN formado (provirus) puede conservarse en el núcleo de diversas células del hospedero y esta propiedad es la causa de las características particulares de las diferentes infecciones debidas a retrovirus. Los integrantes de este género, clasificados actualmente dentro de la subfamilia Orthoretrovirinae, son capaces de inducir la transformación celular neoplásica, aun cuando carecen de un oncogén en su estructura genómica; se ha propuesto que dicha propiedad oncogénica es causa de la falta de sitios definidos de integración al genoma de la célula hospedera (Hauvel et al., 2003).

El virus está relacionado con el Virus Linfotrópico de Células T Humano (HTLV-1, HTLV-2, HTLV-3) y el Virus Linfotrópico de Células T de Simio (STLV-1) desde el punto de vista estructural y funcional (Hulo et al., 2011). El VLB se ha convertido en una herramienta muy importante para el estudio del HTLV 1 ya que la infección que ambos producen es similar afectando las células T y las células B en el caso de VLB, no producen viremia crónica y su organización genética es igual (Aida et al., 2013).

El virus puede trasmitirse por vía vertical a través del calostro o de la leche, aunque, se ha reportado que un $18 \%$ de los terneros procedentes de vacas infectadas, estaban ya infectados al nacer.La vía horizontal (animal-animal) es la de mayor responsabilidad en la transmisión del VLBen esta última se cuentan también las malas prácticas de manejo o transmisión iatrogénica, que promueven la infección entre animales, ya que el VLB se encuentra en secreciones y excreciones que estén contaminados con linfocitos. La transmisión por vía de insectos hematófagos no parece tener relevancia en condiciones naturales (Chamizo, 2005).

Las tres pruebas serológicas comúnmente usadas en el diagnóstico de la enfermedad son: radioinmunoensayo (RIA), inmunodifusión en agar gel (IDGA) y el ensayo inmunoenzimático (ELISA). El IDGA y el ELISA son las pruebas que actualmente recomienda la OIE para el diagnóstico de la infección (OIE, 2008), ellas varían en sensibilidad y especificidad, además, no pueden distinguir entre los anticuerpos adquiridos pasivamente (calostrales) y los adquiridos mediante infección natural. Otra desventaja de estas técnicas es que no pueden detectar animales jóvenes infectados o animales en estadíos tempranos de la infección (Gutiérrez et al., 2011). De otro lado, las pruebas basadas en técnicas moleculares como dot blot y PCR han sido menos utilizadas para el diagnóstico, a pesar de ser útil para la detección temprana del VLB en animales menores de seis meses, evitar reacciones falso positivas causada por transferencia pasiva de inmunoglobulinas

Tabla II. Porcentaje de animales positivos para LP, env, anti-VLB y CP en las razas estudiadas (Percentage of positive animals for LP, env, anti-VLB and CP in the studied breeds).

\begin{tabular}{|c|c|c|c|c|c|}
\hline \multirow[t]{3}{*}{ Raza } & \multicolumn{3}{|c|}{ Muestreo } & \multicolumn{2}{|c|}{ Promedio } \\
\hline & \multirow[t]{2}{*}{ A } & \multicolumn{2}{|c|}{ B } & \multicolumn{2}{|c|}{$C$} \\
\hline & & \multicolumn{2}{|c|}{ Linfocitosis } & $\mathrm{LP}^{+}$ & LP \\
\hline $\mathrm{HV}$ & 11.1 & 3.9 & 29.9 & $15.0 \mathrm{a}$ & 85.0 \\
\hline LUC & 3.4 & 16.7 & 36.7 & $18.9 a$ & 81.1 \\
\hline \multirow[t]{2}{*}{$\mathrm{HOL}$} & 26.0 & 30.0 & 53.0 & $36.3 b$ & 63.7 \\
\hline & env $^{+}$ & & & $e^{e n v^{+}}$ & env \\
\hline $\mathrm{HV}$ & 32.0 & 28.0 & 54.8 & $38.3 a$ & 61.8 \\
\hline LUC & 90.0 & 96.6 & 93.2 & $93.3 b$ & 6.7 \\
\hline \multirow[t]{2}{*}{$\mathrm{HOL}$} & 60.0 & 82.0 & 100.0 & $80.7 c$ & 19.3 \\
\hline & anti-VLB $^{+}$ & & & anti-VLB $^{+}$ & anti-VLB- \\
\hline $\mathrm{HV}$ & 29.0 & 30.5 & 31.5 & $30.3 a$ & 69.7 \\
\hline LUC & 100.0 & 10.0 & 100.0 & $100.0 \mathrm{~b}$ & 0.0 \\
\hline \multirow[t]{2}{*}{$\mathrm{HOL}$} & 60.0 & 82.0 & 100.0 & $80.7 \mathrm{c}$ & 19.3 \\
\hline & $\mathrm{CP}^{+}$ & & & $\mathrm{CP}^{+}$ & $\mathrm{CP}^{-}$ \\
\hline $\mathrm{HV}$ & 21.3 & 20.0 & 15.4 & $18.9 a$ & 72.8 \\
\hline LUC & 40.1 & 57.1 & 48.2 & $48.5 b$ & 51.5 \\
\hline $\mathrm{HOL}$ & 100.0 & 100.0 & 100.0 & $100.0 c$ & 0.0 \\
\hline
\end{tabular}

Letras diferentes en las columnas indican diferencias significativas entre los promedios de las razas. 
a través del calostro y detectar el virus en animales inmunotolerantes (Mohammadabadi et al., 2011).La principal desventaja de la PCR es que las variaciones en la secuencia nucleotídica de algunos aislamientos del virus, podrían inducir a errores en la hibridación de los oligonucleótidos disminuyendo consecuentemente la sensibilidad de la PCR, inconveniente que han sido superado con el diseño de cebadores degenerados como consecuencia de nuevos algoritmos de alineamiento (Jimba et al., 2010).

La leucosis bovina es una enfermedad que pasa desapercibida, ya que algunos animales infectados no presentan signos clínicos, este hecho enmascara la realidad ya que el virus genera pérdidas a nivel productivo y reproductivo, además de ser inmunosupresor y permitir la proliferación de otros patógenos. El virus genera pérdidas económicas por tratamientos secundarios como las repeticiones de dosis vacunales y pérdidas indirectas por fallas reproductivas (Sandez et al., 2006). El intervalo entre partos se alarga y los servicios por concepción se aumentan (Santamaría, 2014). La producción de leche se puede reducir hasta en un 5\% (Cadavid, 2012). La proteína de la leche se disminuye y el recuento de células somáticas se aumenta (Szewczuk et al., 2012).

El VLB es de distribución mundial, siendo los países con mayor prevalencia son España con 90\%, Argentina $84 \%$, Chile $82.5 \%$, Polonia $75.8 \%$, Uruguay 68.6\%, Venezuela 49\%, USA 48\%-52\%, Japón 44\%-80\%, Filipinas y México con 32\% e Irán 15.5\% (Martin et al., 2001; Trono et al., 2001a; Rola y Kuzmak, 2002; Felmer et al., 2006a; Rama, 2009; Matsumura et al., 2011; Mohammadabadi et al., 2011). Los datos de prevalencia en Colombia son variables (Aguilar et al., 1989; Ruiz, 1995; Alfonso et al., 1998; Orjuela et al., 2000; Ramírez et al., 2002; Betancur y Rodas, 2008; Hernández et al., 2011a; Cadavid et al., 2012; Usuga, 2015) dependen de la región de muestreo, del grupo racial estudiado y de la técnica diagnóstica empleada.

En un trabajo anterior reportamos una alta presencia (83\%) del VLB en el ganado criollo Hartón del Valle (HV) (Hernández et al., 2011a) usando métodos moleculares, sin embargo, no se evidenciaron los síntomasclásicos de la enfermedad en dichos animales, lo que puede sugerir que la infección del VLB en el HV transcurre de forma diferente. Por tanto el objetivo de este estudio fue caracterizar la dinámica de infección del VLB evaluando la presencia del virus por métodos moleculares, el desarrollo de linfocitosis persistente, la cuantificación de la respuesta inmune y carga proviral en el ganado criollo HV.

\section{MATERIALES Y MÉTODOS}

\section{ANIMALES Y PROCESAMIENTO DE MUESTRAS}

Se calculó el tamaño de muestra según el valor de prevalencia molecular (56\%) del VLB en ganados del Departamento del Valle del Cauca (Muñoz et al., 2008; Hernández et al., 2011a; Cadavid et al., 2012;) usando la fórmula $\mathrm{n}=z^{2 *} p^{*} q / c^{2}$, donde $p$ y $q$ son las probabilidades de ocurrencia y no ocurrencia respectivamente, z y c son el nivel de significancia y la certeza respecti- vamente (Corva, 2010). Se utilizaron 93 animales puros Hartón del Valle (HV), los cuales se muestrearon tres veces (muestreos $\mathrm{A}, \mathrm{B}$ y C) a intervalo de 4 meses, en cada visita se tomaron muestras de sangre en dos tubos, sin y con anticoagulante $\left(\mathrm{K}_{2}\right.$ EDTA $\left.7.2 \mathrm{mg}\right) \mathrm{y}$ refrigerados hasta su transporte al laboratorio. Adicionalmente se colectaron muestras de las razas Lucerna (LUC) y Holstein (HOL) como se detalla en la tabla I.

Del tubo sin anticoagulante se separó el suero mediante centrifugación a $3000 \mathrm{rpm}$ durante 13 minutos, el cual fue guardado a $-80^{\circ} \mathrm{C}$ hasta su uso. Del tubo con anticoagulante se extrajeron linfocitos de sangre periférica (LSP) según la metodología descrita por Juliarena et al., 2007. El ADN se extrajo a partir de los LSP usando el kit Wizard® Genomic DNA Purification Kit de Promega, siguiendo las instrucciones del fabricante.

\section{DeSARROLlo dE LINFOCITOSIS PERSISTENTE (LP)}

El desarrollo de LP se evaluó mediante la metodología de extendido en placa de sangre periférica. Usando la técnica de empujado, $20 \mu 1$ de sangre periférica fueron extendidos, fijados con metanol al $96 \%$ durante 5 minutos, teñidos con 1\% de Methylene Blue 100x DNA Stain, (AMRESCO®) durante 3 minutos y finalmente se detuvo la reacción con la solución tampón (10 mM Na$\left.{ }_{2} \mathrm{HPO}_{4}, 2 \mathrm{mM} \mathrm{KH} \mathrm{PO}_{4}\right)($ Campuzano, 2008). Las placas fueron observadas con un microscopio óptico (NiKon, eclipse, E200) a un aumento de 1000x y se calculó el porcentaje de linfocitos. Se consideró que el animal evaluado presentó linfocitosis cuando el porcentaje de linfocitos fue igual o mayor a la media más dos veces la desviación estándar para ese sexo y grupo etario. Además, se consideró que un animal tenía LP cuando en dos muestreo seguido presento linfocitosis (Chamizo, 2005).

\section{CuANTIFICACIÓN DEL DESARROLLO DE ANTICUERPOS CONTRA EL VIRUS (ANTI-VLB)}

Los anticuerpos contra el VLB (anti-VLB) se cuantificaron usando un test de ELISA (Svanova, SVANOVIR $^{\circledR}$ BLV gp51-Ab) siguiendo las instrucciones del fabricante. Las placas fueron leídas con un fotómetro para microplacas $\left(\right.$ BioTeK $^{\circledR}$ ELx $808^{\mathrm{TM}}$ ) usando aire como muestra blanco a $450 \mathrm{~nm}$ de longitud de onda. En cada placa se utilizaron controles positivos y negativos suministrados por el kit. Las muestras y los controles se corrieron por duplicado. Los valores de densidad óptica fueron interpretado con el programa xChek 3.3. Los títulos de anticuerpos obtenidos $<15$ se consideraron negativos y los $\geq 15$ se consideraron positivos.

\section{PRESENCIA DEL VLB POR MÉTOdOS MOLECULARES (ENV)}

Mediante PCR-anidada se amplificó una región altamente conservada del gen env viral. En la primera reacción se usaron $25 n g$ de ADN, $10 \mathrm{mM}$ de cada cebador "sentido" env ${ }_{5032}$ 5'-TCTGTGCCAAGTCTCCCAGATA-3' y "anti sentido" env ${ }_{5608 \mathrm{r}}$ 5'-AACAACAACCTCTGGGAAGGGT-3', 0.2 mM de cada dNTP, 1X de tampón de PCR, 2.5 mM de $\mathrm{MgCl}_{2}$ y $1 \mathrm{U}$ de Taq DNA Polymerase $\left(\right.$ Fermentas ${ }^{\circledR}$ ). En la segunda reacción se utilizó como ADN molde $1 \mu 1$ del producto amplificado de la primera reacción, las mismas concentraciones de los demás reactivos y los cebadores internos "sentido" env ${ }_{5099}$ 
5'-CCCACAAGGGCGGCGCCGGTTT-3> y "anti sentido" env ${ }_{5521 r}$ 5'-GCGAGGCCGGGTCCAGAGCTGG-3', haciendose ambas reacciones a un volumen final de $15 \mu \mathrm{l}$ (Monti et al., 2005). El perfil térmico de la primera reacción incluyó una desnaturalización inicial a $94^{\circ} \mathrm{C}$ durante 5 minutos, seguido por 40 ciclos de $94^{\circ} \mathrm{C}$ por 30 segundos, $60^{\circ} \mathrm{C}$ por 30 segundos y $72^{\circ} \mathrm{C}$ por $1 \mathrm{mi}-$ nuto, para terminar con una extensión final a $72^{\circ} \mathrm{C}$ durante 5 minutos. Las condiciones de termociclado de la segunda reacción fueron las mismas, excepto por la temperatura de hibridación que se aumentó a $68^{\circ} \mathrm{C}$. Las amplificaciones fueron llevadas a cabo en un termociclador PTC-100 ${ }^{\circledR}$ Teltier Thermal Cycler (BIO-RAD). Los amplificados se observaron en geles de agarosa al 1.2\% teñidos con bromuro de etidio en una cámara SUB-CELL ${ }^{\circledR}$ GT, (BIO-RAD) y visualizados con luz ultravioleta, el producto de ambas reacciones es un fragmento de $444 \mathrm{pb}$ en los animales portadores del VLB. Se utilizó ADN de un animal positivo y uno negativo como controles de PCR. Para garantizar que en las muestras de ADN no hubiera ningún inhibidor de la PCR cada muestra fue probada amplificando el gen gliceraldehído 3 fosfato deshidrogenasa (GAPDH) según las condiciones presentadas por Janovick et al, (2007).

\section{CUANTIFICACIÓN DE LA CARGA PROVIRAL (CP)}

Esta cuantificación se realizó mediante una PCR cuantitativa en tiempo real (Q-PCR-RT). Con el objetivo de construir la curva estándar, primero de determinó el número de copias/ng de ADN de una muestra siguiendo el método de dilución seriada. Para ello la muestra se diluyó 15 veces en TE $1 \mathrm{X}(1 \mathrm{mM}$ de Tris $\mathrm{HCl}$ pH 7.5, 0.1 mM de EDTA pH 8.0) y se realizó la detección del LTR (long terminal repeat) viral por PCR anidada con los cebadores externos BLTRF-YR (5'-TGTATGAAAGATCATGYCGRC-3'LTR 1-21) y BLTRR (5'-AATTGTTTGCCGGTCTCTC-3'-LTR 515-533) a $10 \mathrm{mM}, 10$ ng de ADN, $0,2 \mathrm{mM}$ de cada dNTP, $1 \mathrm{X}$ de tampón de PCR, $2.5 \mathrm{mM}$ de $\mathrm{MgCl}_{2}$ y $1 \mathrm{U}$ de Taq DNA Polymerase (Fermentas ${ }^{\circledR}$ ) en un volumen final de $20 \mu l$. El programa de amplificación fue $94^{\circ} \mathrm{C}$ por 2 minutos, 35 ciclos de 30 seg a $94^{\circ} \mathrm{C}, 30$ seg a $58^{\circ} \mathrm{C}$ y 30 seg a $72^{\circ} \mathrm{C}$, con un ciclo final de 5 minutos a $72^{\circ} \mathrm{C}$. En la segunda reacción se usó como ADN molde $1 \mu l$ de producto de PCR de la primera reacción. Los cebadores internos 256 (5'-GAGCTCTCTTGCTCCCGAGAC-3', LTR 256-276) y 453 (5'-GAAACAAACGCGGGTGCAAGCCAG-3'LTR 430-454), los demás reactivos y el perfil de amplificación fueron iguales a los utilizados en la primera ronda de amplificación (Jimba et al., 2010). Mediante geles de agarosa al 1,4\% teñidos con bromuro de etidio se determinó en que dilución no hubo amplificación. En esta dilución se realizaron 10 amplificaciones, se anotó la frecuencia de éxito $(\mathrm{f}(\mathrm{x}=0))$ y el número de copias del gen diana $(\lambda)$ fue determinado con el modelo de distribución de Poisson $\lambda=-\log _{\mathrm{e}} \mathrm{f}(\mathrm{x}=0)$ (Jimba et $a l ., 2010)$. Con esta metodología se determinó que la muestra utilizada tenía una concentración de 9,6×10 copias/ng de ADN.

A partir del número de copias estimada en dicha muestra se realizó una curva estándar con las siguientes concentraciones: $1 \times 10^{-1}$ copias $/ \mathrm{ng}, 1$ copias $/ \mathrm{ng}, 1 \times 10^{2}$ copias $/ \mathrm{ng}, 1 \times 10^{3}$ copias $/ \mathrm{ng} 1 \times 10^{4}$ copias $/ \mathrm{ng}, 1 \times 10^{5} \mathrm{co}-$ pias /ng y $1 \times 10^{6}$ copias $/$ ng y $1 \times 10^{7}$ copias/ng. La cuantificación de la CP se realizó mediante una PCR cuantitativa en tiempo real (Q-PCR-RT) amplificando un fragmento de $168 \mathrm{pb}$ utilizando los cebadores degenerados diseñados con el algoritmo CoCoMo CoCoMo6-5'MNMYCYKDRSYKSYKSAYYTCACCT-3' y CoCoMo815'-TACCTGMCSSCTKSCGGATAGCCGA-3', la sonda TaqMan (5'-FAM-CTCAGCTCTCGGTCCNFQMGB-3') (Jimba et al., 2010) y $10 \mathrm{ng}$ de ADN, 2X de iTaq ${ }^{\text {TM }}$ Universal Probes Supermix, 200mM de cada cebador y $200 \mathrm{mM}$ de la sonda FAM en un volumen final de 10ul. Cada estándar de la curva y cada muestra fueron corridas por triplicado.La Q-PCR-RT fue llevada a cabo en un termociclador CFX96 "Real-Time System" (BIO-RAD ${ }^{\circledR}$ ) con el siguiente programa: $50^{\circ} \mathrm{C}$ durante 2 minutos para la activación de la enzima Uracil-DNA Glicosilasa, $95^{\circ} \mathrm{C}$ por 10 minutos para la activación de la iTaq DNA polimerasa, 85 ciclos de 15 segundos a $95^{\circ} \mathrm{C}$ y 1 minuto a $60^{\circ} \mathrm{C}$. Se utilizó el promedio del ciclo al cual se cruza el punto de corte (CT: cycle threshold) para definir el resultado. El valor crítico de clasificación de los animales en alta carga y baja carga proviral fue la mediana $\left(1 \times 10^{5}\right.$ copias $\left./ \mathrm{ng}\right)$.

\section{ANÁLISIS ESTADÍSTICO}

Se calcularon los porcentajes de individuos que desarrollaron linfocitosis persistente $\left(\mathrm{LP}^{+}\right)$y de los que no (LP-); el porcentaje de animales infectados con el virus $\left(\mathrm{env}^{+}\right)$y no infectados (env-); el porcentaje de animales seropositivos al VLB (anti-VLB $)$ y seronegativos (anti-VLB-), además de la cuantificación de anticuerpos anti-VLB y finalmente, el porcentaje de animales que tuvieron presencia del VLB estimada por Q-PCR $\left(\mathrm{CP}^{+}\right)$ y se clasificaron en los que tenían una carga proviral alta ( $\left.\mathrm{CP}^{\text {alta }}\right)$ y carga proviral baja $\left(\mathrm{CP}^{\text {baja }}\right)$.

Se realizaron pruebas de independencia de $\mathrm{Chi}^{2}$ para cada variable (LP, env, anti-VLB y CP) y la edad, el sexo, y la raza. Además de pruebas de independencia de $\mathrm{Chi}^{2}$ entre las variables LP, env, anti-VLB y CP. Las diferencias entre las proporciones se estimaron con base en una prueba exacta de Fischer con un nivel de confianza del $95 \%$, siendo considerados significativos valores de $p<0.05$. Los análisis fueron realizados usando el software SAS versión 9.1.

\section{RESULTADOS}

\section{DINÁMICA DE LA INFECCIÓN DEL VLB}

Solo en la raza HV el porcentaje de animales que presentó linfocitosis disminuyó entre los muestreos A y B para aumentar nuevamente en el C. Sin embargo, en las razas LUC y HOL los animales con linfocitosis siempre aumentaron entre muestreos. Así, los valores de $\mathrm{LP}^{+}$fueron dependientes de la raza $(\mathrm{p}<0.01)$ y a pesar de no variar significativamente en los animales HV y LUC, solo el 15\% de los primeros desarrollaron $\mathrm{LP}^{+}$(tabla II).También se encontró dependencia entre el desarrollo de $\mathrm{LP}^{+}$y el sexo del animal $(\mathrm{p}<0.05)$ de tal manera que ninguno de los machos y el $17 \%$ de las hembras desarrolló $\mathrm{LP}^{+}$. De otro lado, no se evidenció dependencia entre la $\mathrm{LP}^{+}$y edad, aunque el 19\% de los animales menores de 2 años,el $17 \%$ de los animales 
entre 2 y 4 años y el 13.3\% de los animales mayores de 4 años desarrollaron $\mathrm{LP}^{+}$.

La infección medida mediante la amplificación del gen env reveló que el porcentaje de animales infectados aumentó entre muestreos excepto en la raza HV entre los muestreos A y B, y en la raza LUC entre los muestreos B y C. Se encontró dependencia significativa entre la presencia del VLB y la raza $(\mathrm{p}<0.01)$ (Tabla II). Igualmente, la presencia del VLB dependió de la edad del animal $(\mathrm{p}<0.05)$ siendo los animales mayores de 4 años los más infectados (34.4\%), entre los 2 y 4 años la infección fue del $22 \%$ y en los animales menores de 2 años de 19\%. La infección fue independiente del sexo, aunque el $14 \%$ en machos y $27 \%$ en hembras fueron positivos para la amplificación del gen env.

El porcentaje de animales positivos por ELISA en cada una de las razas estudiadas se presenta en la tabla II. El porcentaje de animales infectados aumentó entre muestreos en las razas $\mathrm{HV}$ y HOL mientras que, en la raza LUC se mantuvo constante durante el estudio. El porcentaje promedio de animales seropositivos fue de $30.3 \%$ en $\mathrm{HV}, 100 \%$ en LUC y $80.7 \%$ en HOL, con fuerte dependencia entre el grupo racial y la seropositividad medida por ELISA $(\mathrm{p}<0.01)$. No se encontró dependencia entre la presencia de la enfermedad determinada por ELISA, la edad y el sexo, aunque el rango etario más afectado fue el de mayores de 4 años (26\%), seguido por el rango de entre 2 a 4 años (24\%) y animales con edades inferiores a los 2 años (14\%). La cuantificación de la respuesta inmune estimada con los títulos de anticuerpos (TA) contra el VLB se muestra en la tabla III. En todos los muestreos, tanto en animales positivos como en los negativos, los TA fueron más altos en la raza HV que en la LUC y la HOL. Además, se encontraron diferencias significativas $(p<0.05)$ entre la respuesta inmune de los animales anti-VLB+.

El porcentaje de animales positivos por Q-PCR disminuyó entre muestreos en la raza HV para un promedio de $18.9 \%$, en la raza LUC los animales positivos cambiaron entre muestreos para un promedio final de $48.5 \%$ mientras que, en la raza HOL todos los animales fueron positivos (Tabla II). Esto significó dependencia entre Q-PCR y raza $(\mathrm{p}<0.01)$, al igual que con la edad $(p<0.05)$, de tal forma que los animales del rango etario intermedio fueron los más afectados (39\%) seguido por los mayores de 4 años (22\%) y los menores de 2 años (10\%). La dependencia con el sexo no fue significativa. Los animales $\mathrm{CP}^{+}$se clasificaron de acuerdo a la cantidad de copias provirales como de alta ( $\left.\mathrm{CP}^{\text {alta }}\right)$ y baja (CPbaja) carga proviral, así, solo el $22,8 \%$ del $\mathrm{HV}$, el
48,5\% del LUC y 100\% de los HOL tuvieron CPalta. La cuantificación de la CP se muestra en la tabla IV. En los animales clasificados con CPalta el mayor valor lo presentó la raza HOL (1182992 copias/ng de ADN), seguido por la raza LUC (963831 copias/ng de ADN) y por la raza HV (663828 copias/ng de ADN) con diferencias significativas entre los promedios de las razas. En los animales clasificados con $\mathrm{CP}^{\text {baja }}$ el mayor valor estuvo en la raza LUC (10234 copias/ng de ADN) seguido por la raza HV (5723 copias/ng de ADN) mientras que en la raza HOL ningún animal se clasifico como de $\mathrm{CP}^{\text {baja }}$.

Solo un individuo HV, cinco LUC y ningún HOL, pasó de tener $\mathrm{CP}^{\text {alta a }} \mathrm{CP}^{\text {baja }}$. De otro lado, los animales que pasaron de $\mathrm{CP}^{\text {baja }}$ a $C P^{\text {alta }}$ fue significativamente más alto en la raza LUC (12.2\%) que en el HV (0.67\%) y en el HOL ( $0 \%)$. En ninguna de las razas se presentaron individuos con cambio en su carga proviral de CPalta a cero, pero en el $\mathrm{HV}$ el $24 \%$ de los casos pasaron de no estar infectados a tener CPaja, en LUC el 3.3\% y en HOL el $0 \%$ tuvieron esta misma tendencia. Por el contrario, el cambio de ser negativo a tener $\mathrm{CP}^{\text {alta }}$ ocurrió con una frecuencia de $1.8 \%, 1.11 \%$ y $26.6 \%$ en las razas HV, LUC y HOL respectivamente.

\section{RELACIONES ENTRE LP, ENV, ANTI-VLB Y CP}

No se encontró dependencia entre el desarrollo de LP y anti-VLB y CP ( $\mathrm{p}>0.05)$. Sin embargo, los títulos de anticuerpos (TA) en la raza HV (88.5) en los animales categorizados como $\mathrm{LP}^{+/-} / \mathrm{env}^{+} / \mathrm{CP}^{\text {alta }}$ fue mayor que en las razas LUC (72.8) y HOL (61.5) lo que indica que la respuesta inmune del $\mathrm{HV}$ es mayor que en las otras razas. Mientras que, en los animales $\mathrm{LP}^{+/-} / \mathrm{env}^{+}$/ anti-VLB', las CP fueron más altas en las razas HOL (1633962 copias/ng de ADN) y LUC (887645 copias / ng de ADN) que en HV (386848 copias/ng de ADN). Por otro lado, hubo alta dependencia entre LP y env ( $\mathrm{p}<0.01)$, así, el 32.7\% de los animales HV fueron $\mathrm{LP}^{+}$/ env $^{+}$, esta misma clasificación la presentaron el 94\% de los animales LUC y el 100\% de los animales HOL. También, los animales $\mathrm{LP}^{-} / \mathrm{env}^{+}$fueron el $7.8 \%$ de los $\mathrm{HV}, 90 \%$ de los LUC y el 72\% de los HOL, mientras que, los animales env ${ }^{-} / \mathrm{LP}^{-}$fueron el 92\%, 10\% y $28 \%$ en las razas HV, LUC y HOL respectivamente.

No hubo dependencia entre env y los anti-VLB, aunque, el porcentaje de animales env ${ }^{+}$y anti-VLB ${ }^{+}$fue mayor en LUC y HOL (100\% en ambos) que en el HV (75\%). Un valor que es preciso resaltar es el porcentaje de animales env ${ }^{+} / \mathrm{CP}^{\text {baja }}$, el cual fue más alto en $\mathrm{HV}$ (76\%) seguido por LUC (48\%) y HOL (0\%). Este valor muestra como a pesar de que el HV tiene el VLB los

Tabla IV. Cuantificación de la carga proviral (copias/ng de ADN) en los animales $\mathrm{CP}^{+}$(Quantification of the proviral load (copies/ng DNA) in the CP + animals).

\begin{tabular}{|c|c|c|c|c|c|c|c|c|}
\hline \multirow[t]{3}{*}{ Raza } & \multicolumn{6}{|c|}{ Muestreos } & \multicolumn{2}{|c|}{ Promedio } \\
\hline & \multicolumn{2}{|c|}{$A$} & \multicolumn{2}{|c|}{ B } & \multicolumn{2}{|c|}{$C$} & \multirow[b]{2}{*}{ CPalta } & \multirow[b]{2}{*}{$\mathrm{CP}^{\text {baja }}$} \\
\hline & CPalta & CPbaja & CPalta & $\mathrm{CP}^{\text {baja }}$ & CPalta & $\mathrm{CP}^{\text {baja }}$ & & \\
\hline $\mathrm{HV}$ & 837608 & 6160 & 562421 & 4213 & 591455 & 6796 & $663828 a$ & 5723 \\
\hline LUC & 549222 & 12365 & 1027452 & 4658 & 1314819 & 13679 & $963831 b$ & 10234 \\
\hline $\mathrm{HOL}$ & 1053397 & --- & 1150720 & --- & 1344860 & --- & $1182992 c$ & --- \\
\hline
\end{tabular}

Letras diferentes en las columnas indican diferencias significativas entre los promedios de las razas. 
animales mantienen la $\mathrm{CP}^{\text {baja }}$. La carga proviral del HV se mantuvo levemente por encima de las 100000 copias en los animales env ${ }^{+} /$anti-VLB $^{+} / \mathrm{LP}^{+}$(119526 copias/ ng) y aumentó considerablemente en las otras razas (399674 y 917642 copias/ng de ADN en LUC y HOL respectivamente). La CP promedio más alta se encontró en los animales de la raza HOL clasificados como env $^{+} /$anti-VLB ${ }^{+} / \mathrm{LP}^{+}$(1633962 copias/ng), seguido por LUC (810200 copias/ng) y HV (254978 copias/ng).

La dependencia entre los anti-VLB y la presencia del VLB fue alta $(p<0.01)$, el $20 \%$ de los animales HV fue anti-VLB ${ }^{+} /$env $^{-}, 100 \%$ de los LUC y ninguno de los animales HOL tuvo esta categoría. Ningún animal fue clasificado como anti-VLB $/ \mathrm{CP}^{\text {alta }}$, mientras que, el $67.3 \%$ de los HV, el $48.9 \%$ de los LUC y el $100 \%$ de los HOL fueron anti-VLB ${ }^{+} / \mathrm{CP}^{\text {alta }}$, lo que se tradujo en un alta dependencia entre los anti-VLB y la CP $(\mathrm{p}<0.01)$.

En la figura 1 se muestra el cambio de la carga proviral a medida que progresa la enfermedad. La carga CP puede detectarse en el HV en animales sin anticuerpos anti-VLB, con y sin LP aunque con valores bajos. La CP aumenta en todos los grupos raciales cuando se empiezan a producir anticuerpos contra el virus así el animal se mantenga sin proliferación de linfocitos (LP), siendo significativamente menor el HV y mayor en el

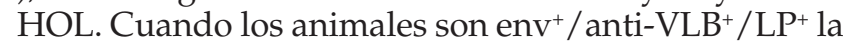
CP aumentó en el HV hasta 254978 copias/ng de ADN, tres veces menos que los animales de la raza LUC y 6.4 veces menos que los animales de la raza HOL.

\section{DISCUSIÓN}

El VLB está ampliamente distribuido en el mundo, en Europa algunos países están libres y otros en proceso de erradicación (Gillet et al., 2007). En Sudamérica la enfermedad se encuentra de forma enzoótica con seroprevalencias de $35.9 \%$ en Chile, $18.4 \%$ en Costa Rica, 77\% en Uruguay y 70\% en Brasil (Usuga, 2015).

Los datos de prevalencia en Colombia son variables. En promedio el porcentaje de infección aquí reportado, medido por ELISA fue del $30.3 \%$ en $\mathrm{HV}, 100 \%$ en LUC y 80.7\% en HOL. FEDEGAN, (2014) en 14 hatos de lechería especializada (985 vacas) durante el 2004, por medio de la técnica ELISA determinó una seroprevalencia del $44 \%$ con variaciones dentro de fincas del 21\% al 85\% debido a características propias de cada hato como el manejo. No existen datos sobre la seroprevalencia de la leucosis bovina enzoótica en el ganado criollo colombiano utilizando métodos serológicos.

En el departamento de Antioquia, Aguilar et al, (1989) estudiaron la prevalencia de LBE en hatos lecheros del Municipio de San Pedro de los Milagros, por medio de la técnica IGDA y encontraron un $12.07 \%$ de prevalencia, el grupo etario de 5 a 9 años fue el más afectado. Ruiz, (1995) encontró un 3.9\% de seropositividad a LBE. Trujillo, (1989) estudió la prevalencia de títulos de anticuerpos en el hato Paysandú (Antioquia) hallando un $14.65 \%$ de infección, mientras que, Ramírez et al, (2002) en tres fincas de Antioquia, con la técnica ELISA, no encontraron presencia de LBE en los terneros, en las novillas la prevalencia fue del 37.5\% y en las vacas del $71.9 \%$. Este último dato difiere del aquí reportado en la raza $\mathrm{HV}$, pero es similar al encontrado en las razas HOL y LUC.

Alfonso et al, (1998) determinaron la prevalencia del VLB en vacas Holstein de la Sabana de Bogotá y los Valles de Ubaté y Chiquinquirá, una de las principales áreas lecheras de Colombia, mediante la técnica de inmunodifusión doble en gel de agar con antígeno gp-51, estableciendo una prevalencia serológica del $45.28 \%$. Utilizando la técnica de inmunodifusión, en bovinos de la Costa Norte de Colombia se detectó la

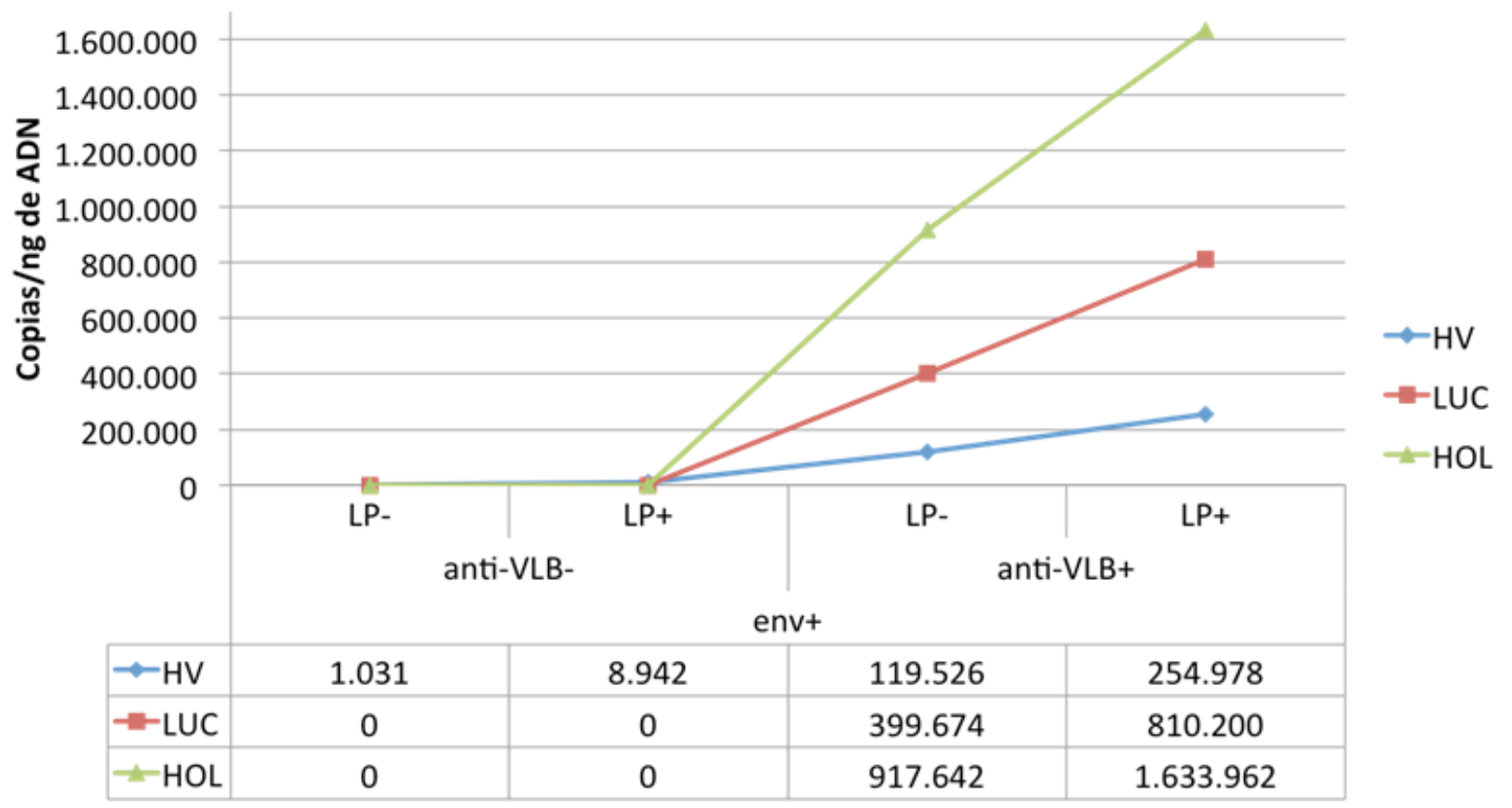

Figura 1. Variación de la carga proviral según el progreso de la enfermedad (Proviral load variation according to the progress of the disease). 
Tabla III. Cuantificación de anticuerpos contra el VLB en los animales positivos (anti-VLB ${ }^{+}$) y negativos (anti-VLB') al virus (Quantification of virus antibodies in the positive (anti-VLB') and negative (anti-VLB') animals).

\begin{tabular}{|c|c|c|c|c|c|c|c|c|}
\hline \multirow[t]{3}{*}{ Raza } & \multicolumn{6}{|c|}{ Muestreo } & \multicolumn{2}{|c|}{ Promedio } \\
\hline & \multicolumn{2}{|c|}{$A$} & \multicolumn{2}{|c|}{$B$} & \multicolumn{2}{|c|}{$C$} & \multirow[b]{2}{*}{ anti-VLB $^{+}$} & \multirow[b]{2}{*}{ anti-VLB } \\
\hline & anti-VLB ${ }^{+}$ & anti-VLB- & anti-VLB ${ }^{+}$ & anti-VLB- & anti-VLB $^{+}$ & anti-VLB- & & \\
\hline $\mathrm{HV}$ & 83.5 & 0.8 & 101.1 & 0.5 & 100.6 & 0.6 & $96.7 a$ & 0.6 \\
\hline LUC & 80.2 & --- & 76.2 & -- & 79.0 & -- & $78.4 b$ & --- \\
\hline $\mathrm{HOL}$ & 57.9 & 0.0 & 60.0 & 0.0 & 64.0 & --- & $60.5 c$ & 0.0 \\
\hline
\end{tabular}

Letras diferentes en las columnas indican diferencias significativas entre los promedios de las razas

presencia del VLB en el 1.5\% animales examinados. El porcentaje de positivos aumentó gradualmente con la edad, de $0.2 \%$ en animales menores de 7 meses, $0.6 \%$ de 7 a 12 meses, y $4.7 \%$ en animales mayores de un año. El $9.4 \%$ y el 1.4\% de los Bos taurus y los Bos indicus, respectivamente, fueron positivos (Orjuela et al., 2000).

En el municipio de Montería departamento de Córdoba se encontró un $21.5 \%$ de positivos a la enfermedad, con mayor seroprevalencia en el grupo etario mayor de 7 años, en las razas cruzadas, en sistemas de producción doble propósito y en hembras (Betancur y Rodas, 2008). Este autor, no se encontró dependencia significativa entre en la edad y el sexo con la presencia de la enfermedad, al igual que en el presente estudio.

El porcentaje de animales HV positivos por PCRanidada fue de $38.3 \%$, este valor fue menor al reportado por Hernández et al, (2011a) (83\%) quien utilizó esta técnica en este grupo racial, este valor pudo ser menor debido a efectos del tamaño de muestra. Este mismo autor presenta porcentajes de infección de 50\% en LUC, que en comparación con el aquí reportado (93.3\%) es menor y 83\% en HOL similar al aquí encontrado. En vacas Holstein muestreadas en el Departamento de Antioquia se reporta una prevalencia molecular del 44\% ( $\mathrm{n}=500$ individuos) (Usuga, 2015) mientras que, acá se representa un prevalencia de casi el doble $(80.7 \%, \mathrm{n}=30$ individuos), las variaciones se deberan a tamaño de muestra y a regiones de muestreo diferentes.

Martin et al, (2001) evaluaron diferentes cebadores en los genes env, pol y tax, en ADN extraído de sangre y leche, todos los cebadores utilizados en las muestras de sangre detectaron el mismo número de animales positivos (94\%) en los genes env y pol y en el gen tax detecto solo provirus en el 78\% de las muestras. En las muestras de leche los valores fueron más variables, encontrando $40 \%$ de positivos con el gen pol, $50 \%$ en el gen env y $0 \%$ en el gen tax. De forma similar, Martin et al, (2001), muestra que el ELISA en suero de sangre detecta 10\% más animales positivos que el ELISA en suero de leche. Algunas razones que pueden explicar estos valores son el periodo de lactancia del animal, así como también el estado sanitario del mismo (mastitis). Estos resultados justifican la elección de las técnicas de laboratorio empleadas (PCR-anidada en el gen env y ELISA) y el tipo de muestra usada (ADN extraído de sangre).

Las variaciones en los porcentajes de infección estimados por cualquier método diagnóstico en el HV se puede deber a: i) los animales fueron muestreados en cuatro hatos, el primero de ellos pertenece a un centro de formación en la cual son constantes las prácticas de manejo como palpaciones donde es un muy difícil controlar la vía iatrogénica de infección; ii) el segundo es uno de los hatos HV más grandes, posiblemente los bajos valores de infección al inicio del estudio se debieron a efectos del tamaño de muestra y la infección aumentó a medida que los animales cambiaron de etapa reproductiva; iii) el tercero es un hato nuevo de aproximadamente 3 años de antigüedad, en su proceso de formación los animales fueron diagnosticados para leucosis, de aquí los bajos valores de infección en esta finca; iv) el cuarto hato es uno de los más antiguos, la variación en la infección de este hato puede deberse a efectos del tamaño de muestra.

Gutiérrez et al, (2011) enseñan como la inmunidad pasiva en animales jóvenes puede alterar los porcentajes de infección medidos por ELISA en un hato con alta prevalencia del VLB. Este hecho puede explicar los resultados obtenidos en las razas LUC y HOL, donde fue más común la infección medida por la prueba de ELISA que por métodos moleculares. Lo anterior también sugiere que puede ser mejor utilizar métodos de diagnóstico directos como PCR-anidad y Q-PCR en hatos con historial de alta prevalencia de leucosis, esto con el fin de evitar resultados falsos positivos debidos a inmunidad pasiva. Por el contrario, métodos indirectos de detección de leucosis (ELISA) pueden ser usados en hatos con baja prevalencia de la enfermedad.

Algunos autores señalan que entre el 30\% y el $70 \%$ de los animales infectados con el VLB desarrollan linfocitosis persistente $\left(\mathrm{LP}^{+}\right)$(Dequiedt et al., 1999; Beyer et al., 2002; Chamizo, 2005; Rama, 2009). En la raza HV los animales $\mathrm{env}^{+} / \mathrm{LP}^{+}$fueron el $32.7 \%$, mientras que, en las razas LUC y HOL los animales con esta condición fueron más ( $94 \%$ y $100 \%$ respectivamente). Rama, (2009) reporta que el $66 \%$ de los animales positivos presenta un recuento de linfocitos patológico.

Dequiedt et al, (1999) reportan, que en los animales con env ${ }^{+} / \mathrm{LP}^{+}$el conteo de linfocitos alcanza el $71.95 \%$, en los animales $\mathrm{env}^{+} / \mathrm{LP}^{-}$de $30 \%$ y en animales env de $25.8 \%$. El conteo de linfocitos fue de $63 \%$ en el HV, $61.64 \%$ en LUC y $65.9 \%$ en HOL en los animales env ${ }^{+}$/ $\mathrm{LP}^{+}$, mientras que, el conteo en los animales env ${ }^{-} /$ LP- fue en promedio de $38 \%$. Por su parte Beyer et al, (2002) no obtuvo diferencias significativas en cuanto al número de linfocitos en los animales env ${ }^{+} / \mathrm{LP}^{-}$y env'. Igualmente Dequiedt et al, (1999) recalca, que en 
promedio el $72 \%(\mathrm{p}<0,001)$ de los linfocitos en animales $\mathrm{env}^{+} / \mathrm{LP}^{+}$, el $37.1 \%$ en animales $\mathrm{env}^{+} / \mathrm{LP}^{-}$y el $37.3 \%$ en animales env ${ }^{-}$realizan apoptosis ex vivo, además, que la respuesta de los linfocitos a la apoptosis puede estar relacionada con factores del hospedero. Rama, (2009) aclara que el recuento celular está influenciado por la edad siendo mayor en animales jóvenes. En los animales menores de cuatro años muestreados el conteo de linfocitos fue en promedio $48 \%$ y en los animales mayores de cuatro años el conteo disminuyó (43\%), igualmente se encontró dependencia entre el desarrollo de $\mathrm{LP}^{+}$y la edad, siendo menor en animales mayores.

Los niveles de anticuerpos, variaron durante el tiempo, alcanzando valores máximos de TA de 101.1 en el HV con promedio de 96.7 (tabla III). La alta dependencia encontrada entre el nivel de anticuerpos y la raza, indica que el $\mathrm{HV}$ tiene una mayor respuesta inmune contra el VLB. Igualmente, la fluctuación en los valores de TA puede deberse según Rama, (2009) a que en épocas cercanas al parto los títulos de anticuerpos contra el VLB disminuyen, la razón más posible es que durante la calostrogénesis los anticuerpos contra el VLB se desplacen de la sangre al calostro, como se ha comprobado que ocurre con las inmunoglobulinas G1 y $\mathrm{M}$ donde el porcentaje de disminución de anticuerpos en sangre es equivalente al aumento de anticuerpos en el calostro.

La carga proviral fue estimada de forma absoluta mediante una PCR cuantitativa en tiempo real usando cebadores degenerados diseñados con el algoritmo CoCoMo (Motivos Coordinados Comunes). Jimba et al, (2010) reporta una alta reproducibilidad, sensibilidad y especificidad de esta técnica. La carga proviral varió durante el tiempo, los altos valores de CP pueden ser debidos a nuevas infecciones y una subsecuente multiplicación de linfocitos, lo que nota de forma marcada en la tasa de infección de las razas LUC y HOL.

Juliarena et al, (2007) clasificaron los animales de acuerdo a la LP y la CP, todos los animales LP- tuvieron $\mathrm{CP}^{\text {baja }}$, esta misma tendencia ocurrió en los animales $\mathrm{HOL}$, pues en $\mathrm{HV}$ el $4.7 \%$ de los animales fue $\mathrm{LP}^{-} / \mathrm{CP}^{\text {alta }}$ y el 33\% del LUC tuvieron esta misma clasificación. Para Juliarena et al, (2007) el $26.5 \%$ y el $40.5 \%$ de los animales fueron $\mathrm{LP}^{+} / \mathrm{CP}^{\text {alta }}$ y $\mathrm{LP}^{+} / \mathrm{CP}^{\text {baja }}$ respectivamente. Solo el $9 \%$ de los animales $\mathrm{HV}$ fue $\mathrm{LP}^{+} / \mathrm{CP}^{\text {alta }}$ y el $91 \% \mathrm{LP}^{+} / \mathrm{CP}^{\text {baja }}$, esto indica que en el $\mathrm{HV}$ los animales que alcanzan a desarrollar $\mathrm{LP}^{+}$, mantiene su carga proviral baja, lo que solo ocurrió en el 35\% de los LUC y en ninguno de los animales de la raza HOL. Gutiérrez et al, (2011) categorizaron al 69.75\% animales evaluados con alta carga proviral, aquí se reporta que el $82.2 \%$ en HOL, el $45.55 \%$ en LUC y el $6.1 \%$ en HV tienen esta clasificación.

La relación ente los títulos de anticuerpos y la CP presentó una alta dependencia entre ambos, Juliarena et al, (2007) reportaron que el 84\% de los animales con $\mathrm{CP}^{\text {baja }}$ no se les pudo detectar anticuerpos contra la proteína viral p24, pero si reactividad contra la glicoproteína gp51, siendo un poco más baja la respuesta inmune en los animales con alta CP que con baja CP. Nuestros datos no reflejan esta tendencia, pero más importante aún es que la respuesta inmune es más alta en el HV que en las otras razas y que la CP proviral es más baja en esta raza que en las otras evaluadas. Estos datos son contrarios a lo reportado por Gutiérrez et al, (2011) quienes no encontraron correlación entre los anticuerpos p24 y la carga proviral.

\section{CONCLUSIONES}

Los datos aquí mostrados indican un fuerte efecto racial sobre la dinámica de la infección con el VLB. El ganado criollo Hartón del Valle, presentó una menor tasa de infección con el VLB, los animales que se infectaron desarrollaron menos linfocitosis, tuvieron una respuesta inmune más alta y mantuvieron un carga proviral más baja en comparación con las razas Lucerna y Holstein. Lo anterior sugiere, que al HV puede ser considerado un progresor lento de la enfermedad.

Una posible estrategia para futuros planes erradicación de la enfermedad, puede ser sustentada en la segregación selectiva basada en la carga proviral, mediante la cual se seleccionen animales jóvenes seronegativos y animales adultos con baja carga proviral.

\section{AGRADECIMIENTOS}

A la Dirección de Investigación de la Universidad Nacional de Colombia Sede Palmira, a los grupos de Investigación en Diversidad Biológica y Recursos Zoogenéticos por la Cofinanciación de la Investigación.

\section{BIBLIOGRAFÍA}

Aida, Y.; Murakami, H.; Takahashi, M. and Takeshima, S. 2013. Mechanisms of pathogenesis induced by bovine leukemia virus asa model for humant-cell leukemia virus. Front Microbiol, 4: 1-11.

Aguilar, L.; Giraldo C. y Velez, R. 1989. Prevalencia serológica de Leucosis Enzootica Bovina en hatos lecheros del Municipio de San Pedro Antioquia. Tesis de grado. Facultad de Medicina Veterinaria y Zootecnia. Universidad de Antioquia Medellin. Colombia.

Alfonso, R.; Almansa, J. y Barrera, C. 1998. Prevalencia serológica y evaluación de los factores de riesgo de la leucosis bovina enzoótica en la Sabana de Bogotá y los Valles de Ubaté y de Chiquinquirá. Rev Sic Tech Off Int Epi, 17: 723-732.

Betancur, C. y Rodas, J. 2008. Seroprevalencia de la leucosis viral bovina en animales con trastornos reproductivos de Montería. Rev MVZ Córdoba, 13: 1197-1204.

Beyer, J.; köllner, B.; Teifke, J.; Starick, E.; Beier, D. and Reimann, I. 2002. Cattle Infected with Bovine Leukaemia Virus may not only Develop Persistent B-cell Lymphocytosis but also Persistent B-cell Lymphopenia. J Vet Med B, 49: 270-277.

Cadavid, L. 2012. Impacto del Leucosis Viral Bovina en la producción de leche. Tesis de Maestría. Facultad de Ciencias Agropecuarias, Universidad Nacional de Colombia, Palmira. Colombia. http://www. bdigital.unal.edu.co/9308/1/lascarioartemocadavidgutierrez.2012. $\operatorname{pdf}(15 / 11 / 2015)$.

Campuzano, G. 2008. ¿̇Cómo obtener un extendido de sangre periférica de óptima calidad. Med Lab, 14: 125-152.

Corva, S.; Silvestrini, M. y Antonini, A. 2010. Manual de bioestadística veterinaria. Corva Santiago. Buenos Aires. Argentina.

Chamizo, E. 2005. Leucosis Bovina Enzootica: Revisión. Redvet, 6: 1-25. Dequiedt, F.; Cantor, G.H.; Hamilton, V.T.; Pritchard, S.M.; Davis, W.C.; Kerkhofs, P.; Burny, A.; Kettmann, R. and Willems, L. 1999. Bovine leukemia virus-induced persistent lymphocytosis in cattle does not correlate with increased ex-vivo survival of B lymphocytes. J Virol, 73: $1127-1137$. 
FEDEGAN. Federación Colombiana de Ganaderos. 2014. Carta Fedegán142: El consumo de sal mineralizada en el sector bovino. Bajo consumo, baja productividad. http://www.fedegan.org.co/ publicaciones/consumo-de-sal-revista-142 (17/03/2016).

Felmer, R.; Zuíga, Z.; Recabal, M. y Chávez, R. 2006. Diagnóstico y tipificación del virus de la leucosis bovina mediante una prueba de PCR-RFLP a partir de ADN extraído desde células somáticas de la leche. Arch Med Vet, 38: 253-257.

Gillet, N.; Florins, A.; Boxus.; M.; Burteau, C.; Nigro, A.; Vandermeers, F. and Willems, L. 2007. Mechanisms of leukemogenesis induced by bovine leukemia virus: prospects for novel anti-retroviral therapies in human. Retrovirology, 4: 1-32.

Gutiérrez, G.; Alvarez, I.; Politzki, R.; Lomónaco, M.; Dus Santos, M.J.; Rondelli, F.; Fondevilla, N. and Trono, K. 2011. Natural progression of Bovine Leukemia Virus infection in Argentinean dairy cattle. Vet Microbiol, 151: 255-263.

Hernández, D.; Posso, A.; Benavides, J.; Muñoz, J; Giovambattista, G. y Alvarez, L. 2011. Detección del virus de la leucosis bovina en ganado criollo colombiano mediante PCR-anidado. Acta Agron, 60: 312-318.

Heuvel, V.; Portetelle, D.; Jefferson, B. and Jacobs, A. 2003. Adaptation of a sándwich enzyme linked immunosorbent assay to determine the concentration of bovine leukemia virus p24 and optimal condition for p24 expressión in short term cultures of peripheral blood mononuclear cell. J Virol Methods, 111: 61-67.

Hulo, C.; de Castro, E.; Masson, P.; Bougueleret, L.; Bairoch, A.; Xenarios, I. and Le Mercier, P. 2011. Viralzone: a knowledge resource to understand virus diversity. Nucleic Acids Res, 39: D576-D582.

Janovick, N.; Dann, H.; Carlson, B.; Murphy, M.; Loor, J. and Drackle, J. 2007. Housekeeping gene expression in bovine liver is affected by physiological state, feed intake, and dietary treatment. J Dairy Sci, 90: 2246-2252.

Jimba, M.; Takeshima, S.; Matoba, K.; Endoh, D. and Aida, Y. 2010. BLV-CoCoMo-qPCR: Quantitation of bovine leukemia virus proviral load using the cocomo algorithm. Retrovirology, 7: 1-19.

Juliarena, M.A.; Gitierrez, S.; and Ceriani, C. 2007. Determination of proviral load in bovine leukemia virus infected cattle with and without lymphocytosis. Am J Fp Res, 68:1220-1225.

Malatestinic, A. 2003. Bilateral exophthalmos in a Holstein cow with lymphosarcoma. Can Vet J, 44: 664-666.

Martin, D.; Arjona, A.; Soto, I.; Barquero, N.; Viana, M. and Gomez-Lucia, E. 2001. Comparative Study of PCR as a Direct Assay and ELISA and $A G I D$ as Indirect Assays for the Detection of Bovine Leukaemia Virus. $J$ Vet Med B Infect Dis Vet Public Health, 48:97-106.

Matsumura, K.; Inove, E.; Osawa, Y. and Okazaki, K. 2011 . Molecular epidemiology of bovine luekemia virus associated with enzootic bovine leukosis in Japan. Virus Res, 155: 343-348.

Mohammadabadi, M.; Soflaei. M.; Mostafavi, H. and Honarmand, M. 2011 . Using PCR for early diagnosis of bovine leukemia virus infection in some native cattle. Genet Mol Biol, 10: 2658-2663.
Monti, G.; Schrijver, R. and Beier, D. 2005. Genetic diversity and spread of Bovine leukaemia virus isolates in Argentine dairy cattle. Arch Virol, 150: 443-458.

Muñoz, D.; Posso, A. y Muñoz, J. 2008. Detección de la leucosis bovina utilizando reacción en cadena de la polimerasa. Rev Colomb Cien Pec, 21: 153-161.

OIE. Organización Internacional de la Salud Animal. 2008. Manual de las pruebas de diagnóstico de las vacunas para los animales terrestres. http://www.oie.int/es/normas-internacionales/manual-terrestre/ (17/03/2016).

Orjuela, J.; Navarrete, A.; Betancourt, L.; Roqueme, E. y Morrison. M. 2000. Salud y productividad en bovinos de la Costa Norte de Colombia. World Anim Rev, 69. http://www.fao.org/3/a-u5700t/ u5700T07.htm\#salud y productividad en bovinos de la costa norte de colombia (17/03/2016).

Rama, G. 2009. Aspectos sobre el diagnostico de leucosis enzoótica bovina. Tesis de Grado. Facultad de Ciencias, Universidad de la República. Montevideo. Uruguay.

Ramírez, N.; Gaviria, G.; Restrepo, L. y Gómez, C. 2002. Diagnostico epidemiológico referente a varias patologías de bovinos en tres haciendas de la universidad de Antioquia. Facultad de Ciencias Agrarias, Universidad de Antioquia. Medellin. Colombia.

Rola, M. and Kuzmak, J. 2002. The detection of bovine leukemia virus proviral DNA by PCR-ELISA. J Virol Methods, 99: 33-40.

Ruiz, I. 1995. Estudio de infertilidad bovina en las zonas lecheras de Antioquia. Faculatad de Ciencias Agrarias, Universidad de Antioquia. Medellin. Colombia.

Sandez, N.; ;lieva, D.; Sizov, I.; Rusenova, N. and lliev, E. 2006. Prevalence of enzootic bovine leukosis in the Republic of Bulgaria in 1977-2004. Arch Vet, 76: 263-268.

Santamaría, J. 2014. Estudio de parámetros productios y reproductivos en vacas seropositivas y seronegativas al virus de la leucosis bovina (BLV) en tres hatos de produccion lechera. Tesis de Maestría. Facultad de Ciencias Agropecuarias, Escuela Politecnica del Ejercito. Pichincha. Ecuador.

Shell, H. and Muller, K. 2004. Case report: lymphosarcoma in a cow. Deut Tierarztl Woch, 111: 38-41.

Trono, K.; Perez-Filgueira, D.; Duffy, S.; Borca, M. and Carrillo, C. 2001 Seroprevalence of bovine leukemia virus in dairy cattle in Argentina: comparison of sensitivity and specificity of different detection methods. Vet Microbiol, 83: 235-248.

Trujillo, L. 1989. Estudio serológico de la Leucosis Bovina en el hato Paysandú. Tesis de Grado. Facultad de Ciencias Agropecuarias, Universidad Nacional de Colombia. Medellin. Colombia.

Úsuga-Monrroy, C.; Echeverri, J. y López-Herrera, A. 2015. Diagnótico molecular del viurus virus de la leucosis bovina en una población de vacas Holstein, Colombia. Arch Zootec, 64: 383-388.

Szewczuk, M.; Zych, S. and Katafiasz, S. 2012. Diagnosis of the bovine leukaemia virus infection in Polish Holstein-Friesian cows and comparison of their milk productivity. Acta Vet Brno, 81: 353-358. 